some is here lethal in double dose, and yet 6 double homozygotes have survived. The possibility that the third chromosome is only semilethal when homozygous, and that no $B a$ individuals appeared by chance, cannot be ruled out completely. Be that as it may, evidence is rapidly accumulating ${ }^{9-11}$ that genetic variants which reduce the viability of their carriers tend to act synergistically. Simultaneous presence in a genotype of several such variants results in a viability lower than would be expected if epistatic interactions played no part. Although the hereditary materials are discontinuous, the development, especially in higher organisms, has the continuity of an integrated process.

Summary.-A low viability, well in the semilethal range, is found in individuals which carry in duplicate (are homozygous for) a certain second and a certain third chromosomes. In the homozygotes for this second chromosome without the third, and for the third without the second, relatively slight reductions of the viability are observed. Simultaneous homozygosis for both chromosomes thus creates a "synthetic" semilethal. Two further examples are recorded, where a second and a third chromosomes, each of which is semilethal in double dose, give a very low viability in the double homozygotes. Epistatic (synergistic) interactions of the components of genetic loads in Drosophila populations appear to be widespread and important.

* The work reported here has been carried out under contract AT-(30-1)-3096, U.S. Atomic Energy Commission.

1 Dobzhansky, Th., Genetics, 31, 269-290 (1946).

2 Wallace, B., J. C. King, C. V. Madden, B. Kaufmann, and E. C. McGunnigle, Genetics, 38, 272-307 (1953).

${ }^{3}$ Spassky, B., N. Spassky, H. Levene, and Th. Dobzhansky, Genetics, 43, 844-867 (1958).

${ }^{4}$ Spiess, E., Genetics, 44, 43-58 (1959).

${ }^{5}$ Spiess, E., and A. C. Allen, Genetics, 46, 1531-1553 (1961).

- Dobzhansky, Th., H. Levene, B. Spassky, and N. Spassky, Genetics, 44, 75-92 (1959).

${ }^{7}$ Gibson, J. B., and J. M. Thoday, Heredity, 17, 1-26 (1962).

8 Dobzhansky, Th., and B. Spassky, Zool. Jahrb. Syst. Okol. Geogr. Tiere, 88, 57-66 (1960).

- Dobzhansky, Th., B. Spassky, and T. Tidwell, Genetics, 48, 361-373 (1963).

${ }^{10}$ Torroja, E., Genetics, 50, 1289-1298 (1964).

${ }^{11}$ Malogolowkin-Cohen, Ch., H. Levene, N. P. Dobzhansky, and A. S. Simmons, Genetics, 50, 1299-1311 (1964).

\title{
CELL-TRANSFORMING ABILITY OF A TEMPERATURE-SENSITIVE MUTANT OF POLYOMA VIRUS*
}

\section{By Michael Fried}

DIVISION OF BIOLOGY, CALIFORNIA INSTITUTE OF TECHNOLOGY, PASADENA

Communicated by Renato Dulbecco, January 18, 1965

Conditional lethal mutants have been shown to be extremely useful in the study of the physiology of viral reproduction and maturation.1, 2 Since such mutants are distributed over most of the genetic map, ${ }^{1,2}$ they could prove to be valuable in the study of tumor viruses. They may be used to "tag" almost all of the viral genes, a property of obvious physiological and genetical implication; they can also 
be useful for studying the mechanisms by which these viruses transform normal cells into cancer cells. For instance, it may be possible to determine, on one hand, which viral functions are needed for the initiation of cell transformation and, on the other hand, which functions are essential for the maintenance of the transformed state. Furthermore, these mutants allow the use of selective techniques and thus provide a sensitive tool for performing marker rescue experiments to find out whether any of the genes of the transforming virus persist in the transformed cells.

This article describes the transforming ability of a conditional lethal mutant of polyoma virus which is temperature-sensitive in the cytocidal virus cell interaction. ${ }^{3}$

Materials and Methods.-Virus strains: The parental large plaque strain of polyoma virus (PY) has been described elsewhere. ${ }^{4}$ The temperature-sensitive mutant (TS-a) was isolated from a stock of PY after nitrous acid treatment. ${ }^{3}$

Cell culture: $\mathrm{BHK} / \mathrm{C} 13$ hamster cells ${ }^{5}$ were obtained from Dr. Michael Stoker of the Institute of Virology in Glasgow, Scotland, and were always cultivated in reinforced ${ }^{6}$ Eagle's medium containing $10 \%$ calf serum and $10 \%$ tryptone phosphate broth.

Transformation assay: The transformation assay was essentially that described by Montagnier and Macpherson ${ }^{7,8}$ which distinguishes the cells transformed by polyoma virus from normal cells by their enhanced ability to form colonies in agar. Hamster cells (BHK/C13) were infected in suspension at a concentration of $10^{6}$ cells $/ \mathrm{ml}$ in reinforced Eagle's medium for $1 \mathrm{hr}$ at $38.5^{\circ} \mathrm{C}$. The infected cells were washed three times with reinforced Eagle's medium to remove the unabsorbed virus and then suspended in $0.33 \%$ agar containing $10 \%$ calf serum and $10 \%$ tryptone phosphate broth in reinforced Eagle's medium at a concentration of $10^{4}$ cells $/ \mathrm{ml}$. One and one-half $\mathrm{ml}$ of the $0.33 \%$ agar cell suspension was plated onto a preset base layer of $5 \mathrm{ml}$ of $0.5 \%$ agar in 60 -mm plastic Petri dishes. After the agar had hardened, the dishes were incubated at $31.5^{\circ}$ and/or $38.5^{\circ} \mathrm{C}$ in well-humidified incubators containing $7 \% \mathrm{CO}_{2}$.

It should be pointed out that under these conditions the seeding of more than $2-3 \times 10^{4}$ cells/ dish, as originally suggested by Montagnier and Macpherson, ${ }^{7,8}$ resulted in the production of many normal cell colonies when incubated at $38.5^{\circ} \mathrm{C}$.

Incubation conditions: The assay dishes were divided into four equal groups which were each incubated in one of the following fashions before scoring for transformation: (1) high-temperature incubation-incubation 16-18 days at $38.5^{\circ} \mathrm{C}$; (2) "shift up" incubation-incubation first for 4 days at $31.5^{\circ} \mathrm{C}$ and then $16-18$ days at $38.5^{\circ} \mathrm{C}$; (3) "shift down" incubation-incubation first for 2 days at $38.5^{\circ} \mathrm{C}$ and then $32-36$ days at $31.5^{\circ} \mathrm{C}$; (4) low-temperature incubation-incubation $32-36$ days at $31.5^{\circ} \mathrm{C}$.

Scoring of transformation: Transformation was usually scored by counting the macroscopic colonies arising after the various incubation periods. Corrections were made for the background of normal colonies by subtracting the number of colonies appearing on the uninfected dishes. In order to verify the transformed nature of a colony, it was picked out of the agar and plated under fluid medium in a plastic Petri dish. After being pipetted free of the agar, the colony usually stuck to the bottom of the dish. Within 1 day at $38.5^{\circ} \mathrm{C}$ or 2 days at $31.5^{\circ} \mathrm{C}$, cells began to migrate out from the colony and started to divide. The transformed colonies grew in a nonorientated crisscross manner in a multilayered mat (loss of contact inhibition). 5 The cells from the normal colonies retained their contact inhibition and grew in an aligned parallel fashion in a single layer. The transformed cells, either as the whole colony or as individual cells, had a great tendency to become dislodged from the substrate under conditions of the slightest agitation. This led to the production of satellite colonies from the parental single colony each time the dish was disturbed. For the most part, the normal colonies did not produce satellite colonies under conditions of slight agitation.

Dishes kept under the low-temperature incubation had a higher background of normal colonies; with these dishes the following procedure was used to estimate the number of transformed colonies. The whole top agar from each dish was removed in medium and transferred to two large plastic Petri dishes $(100 \mathrm{~mm})$. The agar was broken up by pipetting in order to free the colonies. These dishes were then incubated at $31.5^{\circ} \mathrm{C}$ for 3.5 days without being disturbed in order to keep the production of satellite colonies to a minimum. After this incubation period, the colonies were 
fixed by the gentle addition of formaldehyde (final concentration $4 \%$ ) directly to the medium in the plate. The colonies were then stained with methylene blue and scored for the number of transformed colonies by microscopic examination. ${ }^{5}$ By this method too high an estimate can be obtained by counting colonies derived from single cells or pieces of broken colonies. To avoid counting colonies initiated by single cells, only large colonies were scored. This method can also tend to give a low estimate of transformation due to colonies remaining embedded in the agar. When plating single colonies in individual dishes (see above), if perchance a colony is not adequately freed from the agar at the time of the initial transfer, it can be freed at a later time with no ill consequences. When many colonies are transferred into the same dish, it is important that the colonies not be disturbed until after fixation to avoid the production of satellite colonies. Thus, colonies embedded in the agar after the transfer are lost.

Inoculation of hamsters: One- to three-day-old Syrian hamsters were inoculated either subcutaneously (SQ) or intraperitoneally (IP) with 0.1 or $0.3 \mathrm{ml}$ of virus. The young animals were kept as a litter with the mother until they were 18 days old, at which time they were placed in separate cages. The animals were checked twice a day when kept as a litter, and once a day when separated, for death or the production of tumors. Tumors were detected by macroscopic examination only.

Results.-Transformation in vitro: Hamster cells that were exposed to five different concentrations of TS-a $(1000,100,10,1$, and $0 \mathrm{PFU} /$ cell $)$ were plated in agar and incubated under the different temperatures as described in Materials and Methods. The amount of transformation at these different virus concentrations and incubating conditions is presented in Table 1. Each number in Table 1 represents the total number of transformed colonies on 15 replicate dishes.

TABLE 1

\begin{tabular}{|c|c|c|c|c|}
\hline $\begin{array}{l}\text { Input } \\
\text { multiplicity, } \\
\text { PFU per cell }\end{array}$ & $\begin{array}{c}\text { High-temperature* } \\
\text { incubation, } \\
16-18 \text { days } \\
\text { at } 38.5^{\circ} \mathrm{C}\end{array}$ & $\begin{array}{l}\text { "Shift up"* } \\
\text { incubation, } \\
4 \text { days at } 31.5^{\circ} \mathrm{C} \text {, } \\
\text { then } 16-18 \text { days } \\
\text { at } 38.5^{\circ} \mathrm{C}\end{array}$ & $\begin{array}{l}\text { "Shift down"* } \\
\text { incubation, } \\
2 \text { days at } \\
38.5^{\circ} \mathrm{C} \text {, then } \\
\text { at } 31.5^{\circ} \mathrm{C}\end{array}$ & $\begin{array}{c}\text { Low } \dagger \\
\text { temperature, } \\
32-36 \text { days } \\
\text { at } 31.5^{\circ} \mathrm{C}\end{array}$ \\
\hline 1000 & 5 & 504 & 3 & 415 \\
\hline 100 & 1 & 296 & 0 & 225 \\
\hline 10 & 0 & 69 & 0 & 56.7 \\
\hline 1 & 0 & 7 & 0 & 7.5 \\
\hline () & 0 & 0 & 0 & 0 \\
\hline
\end{tabular}

* All the transformed colonies were determined by replating individual colonies under fluid medium as explained in the text.

$\dagger$ All the numbers of transformed colonies were obtained by plating out the whole top agar of 6-8 plates of each set under fluid medium as explained in the text; the numbers are normalized to 15 dishes.

High-temperature and "shift up" incubations: A background of one colony per dish was found by macroscopic examination of the dishes of uninfected cells. In the cases where there were less than 100 colonies per 15 replicate dishes, all the colonies were picked from the agar and tested for their transformed morphology by replating in fluid medium at $38.5^{\circ} \mathrm{C}$. In the instances where there were more than 100 colonies per 15 replicate dishes, a representative number $(60-100)$ of colonies were replated in fluid medium at $38.5^{\circ} \mathrm{C}$. Almost all the colonies so treated stuck to the bottom of the dishes on replating in fluid medium and could be classified as either normal or transformed. In a few cases, colonies were observed which could not be classified. It is not known whether these are normal cell mutants selected by the agar or transformed cells with an unusual morphology.

"Shift down" incubation: Under this incubation condition, a background of three colonies per dish was observed by macroscopic examination of the dishes of uninfected cells. All the colonies arising on all the dishes were picked from the agar and replated in fluid medium at $31.5^{\circ} \mathrm{C}$. Only about 35 per cent of these re- 
plated colonies could be classified as either normal or transformed. Some of the colonies did not stick to the dish on replating. In some of the colonies that stuck, the cells did not migrate out of the colony; in others, the cells migrated but did not divide. Nonclassifiable colonies were observed in approximately the same frequency from the uninfected and infected sets of dishes. Therefore, it is most likely that, for the most part, these nonclassifiable colonies were derived from normal cells. But since this was not shown to be the case, the results presented in Table 1 can only be taken as a lower limit of the transformation under the "shift up" incubating conditions. If one assumes that transformation among the nonclassifiable colonies is in the same proportion as it is among the classifiable colonies, or even if all the nonclassifiable colonies are transformed, it is still found that transformation is greatly inhibited as compared to cells kept at the low-temperature or "shift up" incubations.

Low-temperature incubation: By macroscopic examination, there were about 60-80 normal colonies per dish of cells kept at the low-temperature incubation. This high background hampered any accurate count of the transformed colonies. An estimate of the general number of transformed colonies was made by plating out the whole top agar from 6 to 8 dishes of each virus concentration in fluid medium at $31.5^{\circ} \mathrm{C}$ as described in Materials and Methods.

Since it is not known to what effect the errors involved in plating out the whole top agar affected the true number of the transformed colonies, the results presented in Table 1 for the low-temperature incubation can only be taken as approximate.

The validity of these data, however, is shown by the presence of transformed colonies when the cells were infected by one PFU per cell: since at this input multiplicity not more than one transformed colony was recognized per original dish, the number cannot be an overestimate.

Since the numbers obtained at the various input multiplicities show the same general relationship to each other as those obtained in the "shift up" experiment, it seems that the dose response to the virus is similar in the two cases. However, the considerable similarity between the absolute numbers shown by the table may be spurious.

Transformation in vivo: In a preliminary experiment to test the tumor-producing ability of the mutant, 5 three-day-old hamsters were inoculated subcutaneously with $10^{6}$ PFU of TS-a. All five animals developed subcutaneous fibrosarcomas about the site of inoculation 40-90 days after inoculation. No tumors were found associated with the internal areas of the body. A hemagglutination inhibition titer $^{9}$ of 1280 was detected in the sera of one of the tumor-bearing animals (the only animal so tested) 90 days after inoculation. Usually the wild type (PY), when inoculated under similar conditions, causes angiomatous tumors of the liver and lungs and tumors of the internal organs predominantly in the kidneys and heart. ${ }^{10}$

In order to test whether the tumors induced by TS-a were truly restricted to the subcutaneous site, possibly due to the lower temperature in this area, the experiment was repeated on a larger scale, using different routes of inoculation. One-to three-day-old hamsters were inoculated either subcutaneously or intraperitoneally with either $9 \times 10^{6}$ PFU of TS-a or $2.7 \times 10^{7}$ PFU of PY and observed for 70 days.

The results of this experiment are presented in Table 2. All the animals inoculated with PY, either through the SQ or IP route, died from the rupture of angiomatous tumors of the liver or lungs between 12 and 40 days after infection. Very few 
of the TS-a-inoculated animals died as a direct effect of the virus but were sacrificed when their tumors became too burdensome or at the end of the experiment. Except for some PY-infected animals that were lost previous to the 16th day after inoculation, all had, in addition to the angiomatous tumors, macroscopic tumors of the internal organs mainly in the heart and kidneys. Subcutaneous tumors were only detected in those PY animals which survived for the longest time. On the contrary, only three (two SQ and one IP inoculated) TS-a-infected animals had any indication of angiomatous tumors of the liver at the time of death. Only one TS-ainfected animal had an internal tumor associated with an internal organ (heart). All the other internal tumors were either free or found to be loosely connected to the internal body wall.

TABLE 2

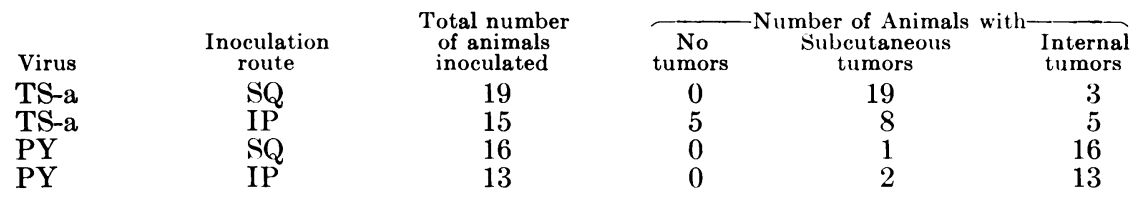

The total number of tumors at the different sites for each type of inoculation adds up to more animals than were inoculated, since some animals had tumors at more than one site.

The results presented here clearly indicate that there is an inhibition in hamsters infected with TS-a, either by a SQ or IP route, of both the angiomatous tumors of the liver and lungs and the production of tumors of the other internal organs that are found in the early stages of PY infection.

Discussion and Conclusions.-The results presented here show that TS-a is temperature-sensitive in its transforming ability. It appears that after completion of the temperature-sensitive step at one temperature (either $31.5^{\circ} \mathrm{C}$ or $38.5^{\circ} \mathrm{C}$ ) the effect on the transformation produced, at least for the most part, cannot be reversed by then shifting the infected cells to the other temperature.

Because of technical difficulties involved in determining the transformation rate at the low temperature, the exact degree of inhibition of transformation (transformation inhibition factor) caused by the temperature-sensitive gene at $38.5^{\circ} \mathrm{C}$ is not known. At $1000 \mathrm{PFU} /$ cell there is a 100 -fold decrease in the production of transformed colonies in infected cells kept at the high temperature for the whole incubation period, compared to cells exposed to the "shift up" incubation. Since in the "shift up" incubation the infected cells were kept at $31.5^{\circ} \mathrm{C}$ for only 4 days, the true transformation inhibition factor created by high temperature at $1000 \mathrm{PFU} /$ cell may even be greater than 100-fold. It is not known whether the transformation produced at $38.5^{\circ} \mathrm{C}$ is due to leakage, revertants, or is a consequence of just the initial virus input.

The temperature-sensitive gene involved in TS-a is needed for the initiation of the transformed state, but not necessarily for the maintenance of this state. This is true since the cells transformed at $31.5^{\circ} \mathrm{C}$ retain their transformed characteristics upon cultivation at $38.5^{\circ} \mathrm{C}$. This observation is reminiscent of the temperaturesensitive sex factor of $E$. coli. ${ }^{11}$ This sex factor is sensitive to high temperature when replicating autonomously but insensitive when integrated with the host genome. But this result is also compatible with a hit-and-run effect of the virus, i.e., once the effect of the virus on the cell producing transformation is completed, 
no portion of the virus genetic material is needed any longer for the maintenance of the transformed state.

It is interesting to remark that the quantitative aspects of the transformation covered by this mutant in the "shift up" incubation are similar to those covered by a nontemperature-sensitive strain of the virus at $37^{\circ} \mathrm{C} .{ }^{7,8}$ With TS-a, in fact, approximately $3 \times 10^{4} \mathrm{PFU}$ are needed to produce one transformed colony; the dose response curve begins to level off between 10 and 100 PFU per cell; the maximum proportion of transformed cells is at least 0.2 per cent.

The in vivo results are consistent with TS-a also being temperature-sensitive in the animal. One could postulate that transformation more readily takes place at the subcutaneous site because of the lower temperature of this area compared with the internal organs. The increased resistance to the neoplastic effect of the virus when inoculated by the IP route ( 30 per cent of the animals inoculated by this route had no detectable tumors) might be due to the slower growth of the virus because of the higher temperature, allowing the immunological mechanisms of the animal to fight off the oncogenic response.

Summary.-A mutant of polyoma virus which was isolated by its temperature sensitivity in the cytocidal virus cell interaction has also been found to be temperature-sensitive in its ability to convert normal hamster cells to neoplastic cells in vitro. The activity of the gene involved has been shown to be required for the initiation, but not for the maintenance of the transformed state.

The author wishes to thank Professor Renato Dulbecco and Dr. Marguerite Vogt for their advice, encouragement, and stimulation in the pursuit of this work, and also for their many helpful discussions and suggestions in the preparation of this paper.

* This work was supported in part by a grant (112) from The Nutrition Foundation, and was aided by a USPHS graduate training grant (5T1 GM86).

${ }^{1}$ Edgar, R. S., G. H. Denhardt, and R. H. Epstein, Genetics, 49, 639 (1964).

${ }^{2}$ Epstein, R. H., A. Bolle, C. M. Steinberg, E. Kellenberger, E. Boy de la Tour, R. Chevalley, R. S. Edgar, M. Susman, G. H. Denhardt, and I. Lielausis, in Synthesis and Structure of Macromolecules, Cold Spring Harbor Symposia on Quantitative Biology, vol. 28 (1963), p. 375.

${ }^{3}$ Fried, M., submitted for publication.

4 Dulbecco, R., and M. Vogt, Virology, 16, 41 (1962).

5 Macpherson, I., and M. Stoker, Virology, 16, 147 (1962).

6 Vogt, M., and R. Dulbecco, these Procesdings, 49, 171 (1963).

7 Montagnier, L. and I. Macpherson, Compt. Rend., 258, 4171 (1964).

${ }^{8}$ Macpherson, I., and L. Montagnier, Virology, 23, 291 (1964).

9 Rowe, W. P., J. W. Hartley, J. D. Estes, and R. J. Huebner, J. Exptl. Med., 109, 379 (1959).

${ }^{10}$ Stewart, S. E., Advan. Virus Res., 7, 61 (1960).

11 Jacob, F., S. Brenner, and F. Cuzin, in Synthesis and Structure of Macromolecules, Cold Spring Harbor Symposia on Quantitative Biology, vol. 28 (1963), p. 329. 